\title{
Research and Application of Control Systems of Auxiliary Engines in Cogeneration Power Station
}

\author{
Sun Jianjun \\ Jiangsu Datang International Power Generation lvsi port \\ Co.,Ltd \\ Jiangsu, China
}

\author{
Liu Xiangdong \\ WuHan KAIDI Electric Power Engineering Co.,Ltd \\ Wuhan, China \\ 1w2008-12@163.com
}

\begin{abstract}
For the control unit in the level of automationassisted workshop relatively backward status quo and Put forward its own solution. Auxiliary control of the integrated development of the need for an analysis, the use of Planning and design theory. Based on the current status quo at home and abroad auxiliary control system. Combined with large A power plant refining Power center for specific circumstances. from the system on a high degree of integration of the auxiliary control architecture as well as the feasibility study carried out feasibility studies Proposed Des Net control system design Program. Through the auxiliary control Program with the traditional comparison. The Paper Proposes major oil refinery. A power plant refining Power Center to be used controlled auxiliary control system. Implementation of the system in the traditional auxiliary system control and monitoring Based on the use of today's industry most Powerful Siemens PCS7 system with high reliability. A power plant refining Power center is now generating a Project. Auxiliary systems are mostly single-loop control and Process control requirements fail to take up a lot of manpower. This article will also be Practical Problems to solve on-site as a Starting Point. Choose recycled water dosing system as the research objectives. combined with fuzzy control theory. The dosing system to analyze the Process, to find a suitable site control methods.
\end{abstract}

Keywords-Thermal Power Plants, Auxiliary control, Fuzzy control, Siemens PCS7, Anxiliary control net

\section{INTRODUCTION}

With the rapid development of industrial automation technology, power plant poses increasing demands for the automation of control systems of auxiliary engines. In the design of those systems in thermal power plant, control systems are separately designed in terms of respective systems of water, ash and coal in a traditional way based on functions of auxiliary control equipment, which otherwise are frequently controlled by systems from different manufacturers, and thus upper computer's SCADA systems are often changing, more requirements for field operators and maintainers as well as increased costs of operation[1] and maintenance. In order to ensure good and efficient performance of the equipment, raise labor productivity, improve the overall quality of operators, and eliminate the traditional control system generally based on separate water, ash and coal systems, this paper develops a new idea for constructing only a centralized balance of plant (BOP) system and integrates its data into MIS system, by taking case of the central engineering of A power plant refinery power plant to analyze the structure and features of BOP system in power plant.

\section{INTRODUCTION OF ENGINEERING TECHNIQUE}

\section{A. Ash Removal System}

Flying ash in the deduster is conveyed by the positive pressure dense-phase pneumatic conveying system on a bin pump in two divisions. One division is exported to the ash storage bank. On the upper part, there're bag filter, pressureand-vacuum release valve and a top terminal box. On the lower part are two discharge ports, one for installing a wet mixer where dry ash is mixed with appropriate water and then carried by an auto-dumping truck to the ash yard for roller compaction and storage. The other port is installing a dry ash bulk machine for outer comprehensive utilization when carried in a truck, with a gasification tank installed in the operating layer of ash bank. Additionally, an air electric heater is designed for the ingression of compressed air through outer tubes, which is used for aerification. Heating up by electric heater, the air goes through the gasification chute in the bottom of the ash bank into carborundum gasification board on the chute to make fluidized flying ash in the bank as for smooth discharge without bridges. The other division is conveyed to fly ash housing in the stokehold for recirculation.

\section{B. Deslagging System}

Deslagging system refers to the control of a whole process involving the conveyance of cinder in slag conveyor and crusher to slag storehouse. Under the sub-atmospheric pressure caused by pulverized coal furnace of boilers, natural wind-a kind of wind generated by the pressure imposed by circulating fluidized bed (CFB) using secondary air fan, expels from the outside into the inner side of dry-type slag extractor, cooling off HT slag with huge amount of heat into those cold slag for direct storage and delivery, by which the generated hot air goes directly into boiler furnace and brings back the heat taken by slag into furnace again. Heat loss is reduced and the efficiency of boiler is enhanced. Collected by the slag cooler, slag is conveyed by the positive pressure dense-phase pneumatic conveying system on a bin pump to slag storage house. On the upper part, there're bag filter, pressure-and-vacuum release valve and a top terminal box. It works just in the same way as what's described in the ash removal system. 


\section{Circulating Water Chemical Feed System}

Just in the same way as the limestone conveying system works, circulating water chemical feed system finishes work by the controller PS7-400H, which can achieve the control of ash removal system and limestone conveying system. Connecting with CPU $400 \mathrm{H}$ and ET200M by a redundant DP bus, the system can enable the control of chemical feed system.

Cooling water recycles in the circulating water system for use. The flow velocity changes as temperature of the water rises up. When water evaporates, various inorganic ions and organic substances become condensed. Cooling tower and ponds are outside exposed to sunshine, wind and raining, along with dust and impurities permeating. All these effects with elements in the structure of equipment and their materials synthetically results in a series of problems just like heavy adherence of deposits, serious corrosion of equipment and massive proliferation of microbe, and consequently pipeline blockage, which would jeopardize the safety in production and cause damage to the factory, or even a big economic loss. Therefore, chemical feed system must be designed in the circulating cooling water system for the stabilization processing of water quality with puritabs water purification equipment to kill microbe so as to guarantee the normal operation of circulating water system.

The system is divided into two parts: the first is generally mechanical part, which contains motor agitator, solution tank, piping, chemical feed pump, filter, level meter in medicine chest, manometer, buffer, safety valve, check valve, globe valve. And the other refers to the control of appliance, mainly involving appliance control cabinet, electric components and cables. The main part of chemical feed system is stainless steel structure. Manual valves on the dilution water pipes are low pressure stainless steel ball valves, and it's the same with pipeline valves before the pump. In the back of the pump are stainless steel HP check valves and HP stop valves.

The chemical feed control system of the controlled object is the one featuring with strong couplings, big inertia and pure time delay. During the runtime, variations of its operational or environmental parameters are hard to be precisely controlled by a simple and traditional method for the measurement of chemical feed, as higher water temperature, changing water velocity and water evaporation can easily result in discrepancies in the system. Chemical feed system consists of four metering pumps, which work in an interlocking way by varying concentration of reagents in circulating pipes. Now, fuzzy control is applied in the control of circulating water chemical feed system after a lot of operational experienced is collected on spot and produced into control rules. Based on a massive selection of those rules, a method for designing fuzzy controller in the feed control system is presented. According to a practical debugging process as well as the analysis of working principle of chemical feed system, knowledge base of control rules is established and fuzzy control inference engine is designed, which guarantees the stable operation of the feed system. Primary study is carried out with regards to feeding volume varying along with the evaporation of circulating water of the chemical feed control system in different seasons and environments, to which the approach is proposed too.

Power center is supporting facility of common engineering parts for the refinery engineering[2], which provides refinery and petrochemical equipment and living conditions with necessary steam (3.6MP at $\mathrm{zss} .7 \mathrm{t} / \mathrm{h}$ ) and electric power $(12 \mathrm{oMw})$. In the power center builds a circulating water field at $2700 \mathrm{om} 3 / \mathrm{h}$, which includes many auxiliary facilities like cooling tower, circulating water pump building, decontamination water system, chemical \& chlorine feed system, monitoring heat exchanger. Local manual operation and remote automatic control will be effected only when those systems work together with reagent pump and blow-down valve. On the upper computer, the control of equipment can be achieved by continuous and/or periodic turn-on (by input time), and there's remarkable indication for its running conditions. Finally on the main screen displaying information of monitoring items are $\mathrm{PH}$, ORP, electrical conductivity, water adding temporality and/or cumulative discharge, cycles of concentration and so on. The application of fuzzy control in circulating water chemical feed system in the engineering is expected to make satisfying results.

\section{ESTABLISHMENT OF COMPUTER NETWORK IN CONTROL SYSTEMS OF AUXILIARY ENGINES}

\section{A. Constitution of the Network Structure}

The network systems of BOP in A power plant refinery power center consists of such ten subsystems as two CFB bag dust catcher systems, limestone pneumatic conveying system, pneumatic ash removal system, pneumatic slag conveying system, circulating water chemical feed equipment and petroleum coke conveying system, along with a suite of Siemens' S7-400H and many remote ET200M I/O modules. The communication among the distance between ET200M and control station is realized in the way of PROFIBUS DP, while the form of redundant industrial Ethernet is used for communication between control station and upper computer and redundant optical fiber communication is available between control station and operator's station in the central control room of the plant, setting up the control system of auxiliary equipment independent from DCS control system. By communicating with DCS system with the advantage of RS485 MODBUS RTU, auxiliaries' central control system sends their information to DCS system and then to MIS system of the plant by DCS system.

Balance of plant have higher requirements for PLC, which refer to the following aspects: as it requires a highlevel control of the power plant, it's necessary to select Siemens' PS7-400H duplicate hot standby system for the control system and multi-functional Siemens' PCS7 for SCADA software. In order to maintain reliability of power source, subsystems should take use of redundant source. After the optimization of model option and design of $\mathrm{I} / \mathrm{O}$ 
modules, those with hog-plugging functions are selected. In BOP network of A power plant refinery power center, we make full use of powerful functions of PCS7 software to solve problems and difficulties in the control system. For communication, we utilize industrial Ethernet to construct $100 \mathrm{MB}$ network based on TCP/IP protocol and long-distance optical fiber transmission. CP443-1 communication modules are connected by twisted pair cables to redundant switches[3]. The distance between ach system and auxiliary control network is generally shorter than $1 \mathrm{KM}$ in the whole plant. So with the use of multimode fibers, the speed gets better, information transmission method and mechanism more appropriate, thus resulting in fairly robust real-time.

\section{B. Description About PCS7 Modules}

Siemens $57-400 \mathrm{H}$ PLC modules are of better dependability by taking advantage of modern massive IC technology and being made by strict manufacturing technique with anti-interference technology of state-of-theart adopted in the interior circuits. Also, PS7-400H has ability for self-checking malfunction of hardware and immediately sends alarm when in failure. Self-diagnostic programs of peripheral components can be compiled into PCS7 to enable circuits and equipment apart from PLC in the system to receive self-diagnostic protection from failure as to make the overall system more reliable. All modules can work in a hot-plugging way without shutting down the system, reduced workload and easy maintenance. LED indicators can visually display working conditions of CPU and I/O templates, which greatly facilitates for quick examination over failure and the maintenance.

\section{The CONTROL MOdE IN BOP System}

There're three modes of operation in BOP system: remote automation, remote manual operation and local manual operation. Remote automatic operation is a normally primary mode. The whole technical process of the system is completed in operators' station based on the satisfaction of the condition of automatic sequential operation. When compiling a program, we should pay attention to the automatic sequential operation as occurrence of any failure or operator breaking off signals would interrupt running programs and turn them back to be safety. Those errors or orders will then appear in the screen in real-time. Remote manual operation refers to the action by operator clicking the controlled target on the computer screen. While in remote manual mode of operation, the system provides rich information involving user guide, helping advice and feedback to direct the operation in avoidance of false operation. In local mode, operators control objects by means of local control box due to the interconnection between local area and the operation of remote programs.

\section{Configuration and Debugging of The System}

\section{A. Configuration}

The control system makes use of PLC modules of Siemens' S7-400H series. In the whole system, there're 352point on-off output, 496-point on-off input and respective 4point and 30-point analogue output and input. An additional $15 \%$ is reserved for necessary points when in design.

\section{B. Debugging}

Before the field installation is not completed for construction, offline debugging can be performed for the control system, which would help check whether the configuration is proper, both its logic relation and sequential control meet technical requirements[4]. Offline debugging can be done in PCS7 by the analog of field signals as to suffice the condition for program execution.

When every single system finishes debugging, complete debugging starts. All supporting systems of two boilers go into operation. Debug Ethernet communication between dedusting \& ash removal control rooms and the master control room. Upload images of upper computers in engineer station to the two operator stations in the master control room via Ethernet network.

\section{SUMMARIES}

The application of balance of plant (BOP) has proven to greatly improve automation level and save labors in auxiliary shops based on the analysis of BOP networking and debugging. In the meantime, higher requirements are presented for operators, which from another side promote them to upgrade their technological and operating levels together with a rapid improvement of operation of the power plant. The gradual maturity in network technique, computer technology and PLC control methods will lay a solid foundation for as such systems going into BOP system. As user's demands vary from time to time, circulating water system, electric secondary circuit, sewage system, hydrogen generation system as well as air compressor system will become part of BOP system.

\section{REFERENCES}

[1] Ben-bbdennour,Adel;Lee,KwhgY.Edwards,RobertM.Multivariable or bust Control of a Power Plant dearator[J].IEEE Transactions on Energy Conversion V8 n 1Mar 1993.1993:123-129.

[2] Zhang yanyu Application of Fuzzy Adaptive Controller in Adding Medicament Control of Water Treatment [J].China Instrumentation, $2007,12: 45-47$.

[3] Chu Zhenyu Xu zhongren Tong Huiyan. Adding Drugs Control System of Industrial Circulatory Water Based on S7-300PLC [J]. Computer Measurement \& Control, 2005, 13:555 - 558.

[4] Young-Moon Park; Myoen-Song Choi; An auxiliary LQG/LTR robust controller design for cogeneration plants[J] Energy Conversion, IEEE Transactions on 1996407 - 413 